\title{
Teaching for wisdom: what matters is not just what students know, but how they use it
}

\author{
Robert J. Sternberg, ${ }^{a *}$, Alina Reznitskaya ${ }^{b}$ and Linda Jarvin ${ }^{a}$ \\ ${ }^{\mathrm{a}}$ Tufts University, USA; ${ }^{\mathrm{b}}$ Montclair State University, USA
}

This article describes a balance theory of wisdom and applies the theory to the context of schooling. First the article discusses why cognitive skills as assessed by conventional tests are an important, but not a sufficient, basis for education. Second the article discusses the concept of wisdom and why it is important for schooling. Third the article presents a balance theory of wisdom, according to which wisdom is defined as the application of intelligence, creativity, and knowledge toward the achievement of a common good through a balance in the (a) short- and (b) long-terms; among (a) intrapersonal, (b) interpersonal, and (c) extrapersonal interests; in order to achieve a balance among (a) adaptation to existing environments, (b) shaping of existing environments, and (c) selection of new environments. Fourth the article discusses how wisdom might be nurtured in schools. It is concluded that it might be worthwhile for schools to emphasize the development of wisdom.

\section{Introduction}

A few years ago, one of us was on his way to an important meeting but got stuck in a maddening traffic jam. As he approached an exit along our slow, bumpy and obstacle-laden route, he observed that the highway that extended out from the exit, which was perpendicular to the direction in which he was going, was wonderfully paved and the traffic was moving rapidly with no obstacles along its course. He considered taking that route. There was only one problem: the route led nowhere he wanted or needed to go, nor that he should have gone. Nevertheless, it was just so tempting. After all, the route led somewhere! Since then, many times when he has been in horribly long lines for flights to his destination, or has seen one flight after another to that destination cancelled, he has been tempted to go somewhere else where it is easier and quicker to go.

\footnotetext{
*Corresponding author. Tufts University, Ballou Hall 3rd Floor, Medford, MA 02155, USA. Email: Robert.sternberg@tufts.edu
} 
Education has taken the easier, quicker route. It leads students rapidly and relatively smoothly - in the wrong direction. That wrong direction is illustrated by the high-stakes systems of testing that have come to dominate the UK as well as the US. It is not that highstakes testing is, in itself, necessarily bad. It is that what the tests measure, to a large extent, doesn't matter all that much in the long run. What matters is not only how much knowledge you have, but how you use that knowledge-whether for good ends (as for Mahatma Gandhi or Martin Luther King) or for bad ones (as for Adolf Hitler and Joseph Stalin). In this article, we argue that what matters most of all is the development of wisdom.

The purpose of education is to develop not only knowledge and skills, but the ability to use one's knowledge and skills effectively. Many societies today are preoccupied with the development of knowledge and basic cognitive skills in school children. But are knowledge and basic cognitive skills - the essential ingredients of intelligence as classically defined (see Herrnstein \& Murray, 1994)—enough? Consider the following.

Flynn (1998) has pointed out that in more than a dozen countries for which records have been available, IQs have been rising roughly at a rate of 9 points per generation (30 years). This increase has been going on for at least several generations (see also Neisser, 1998).

With IQs going up and IQ-related abilities counting more and more for success in the society, one can only conclude that the IQ-like abilities of those at the top of the socioeconomic spectrum are higher than ever before-even higher than would be predicted merely by the 'Flynn effect', because IQs have become more important for gaining access to higher education and premium jobs. But again, the rise in IQs among the socioeconomic elite does not seem to have created a happier or more harmonious society, and one only has to read the daily newspapers to see examples of the poor uses to which high IQ can be put. Judging by the amount, seriousness, and sheer scale of global conflict, perhaps not much of the increase in IQ is going towards creating a common good. Certainly there is no reason to believe that increasing IQs have improved people's or nations' relations with each other. Indeed, today there is more terrorism than at any time in recent memory. In the 1990s, there were more genocides and massacres than at any time since the Second World War. As people became smarter, they became, if anything, less wise and moved further from - rather than closer to-the pursuit of a common good. Indeed, there seems to be a great deal of hate in today's world (Sternberg, 2003).

The memory and analytical skills that are so central to intelligence are certainly important for school and life success, but perhaps they are not sufficient. For one thing, there is more to intelligence than just these skills (Gardner, 1983; Sternberg, 1997). For another thing, one can be smart but foolish. We have seen this in political leaders and in business leaders, such as at Enron, Arthur Andersen, WorldCom, and elsewhere. Smart but foolish people are susceptible to one or more of six fallacies (Sternberg, 2002), which we will illustrate with the use of Enron:

- Unrealistic optimism. They believe they are so smart that whatever they do will work out just fine, regardless of whether it really makes sense. Top-level executives at Enron believed they could create shell companies to hide losses and that all then would be all right. 
- Egocentrism. They start to view decisions only in terms of how the decisions benefit them. Top Enron managers enriched themselves at the expense of shareholders, employees, customers and other stakeholders.

- Omniscience. They think they are all-knowing; they don't know what they don't know. Top Enron managers believed they knew how to run a company, and as a result, failed to learn from mistakes.

- Omnipotence. They think they can do whatever they want. Top Enron managers engaged in accounting fraud, even though they knew it was illegal.

- Invulnerability. They think they are so smart they can get away with anything they do. The top Enron managers thought they could get away with insider trading and misleading the public.

- Ethical disengagement. They tend to ignore the ethical dimension of the problems they face, believing themselves to be above such matters. They view ethics as importantbut for other people. Top Enron managers ignored ethical principles in the way they ran their business.

Students and teachers alike can realize that fallacies such as these are not just mistakes 'other people' make. We all are susceptible to foolish thinking. Indeed, the 'smarter' we are, the more we may think ourselves immune. And it is this fantasy that we are immune that makes us all the more susceptible. Arguably, wisdom is at least as important as, or even more important than, sheer knowledge and intelligence. Thus, promoting the development of wisdom in schools represents a clear need and responsibility.

\section{What is wisdom?}

Wisdom can be defined as the 'power of judging rightly and following the soundest course of action, based on knowledge, experience, understanding, etc' (Webster's new world dictionary, 1997, p. 1533). A number of psychologists have attempted to understand wisdom in more variegated ways. The approaches underlying some of these attempts are summarized in Baltes and Staudinger (in press), Sternberg (1990, 1998a), and Sternberg and Jordan (2005). It is beyond the scope of this article to review all these different approaches.

Wisdom is defined here as the application of intelligence, creativity, and knowledge as mediated by values toward the achievement of a common good through a balance among (a) intrapersonal, (b) interpersonal, and (c) extrapersonal interests, over the (a) short- and (b) long-terms, in order to achieve a balance among (a) adaptation to existing environments, (b) shaping of existing environments, and (c) selection of new environments (Sternberg, 1998a, 200I), as shown in Figure I. We make no claim that ours is the only definition of wisdom (see Sternberg \& Jordan, 2005) or even the 'best' one. It is, however, a definition we have found to be useful in designing a program for developing wisdom in young students.

Thus, wisdom is not just about maximizing one's own or someone else's self-interest, but also about balancing off various self-interests (intrapersonal) with the interests of others (interpersonal) and of other aspects of the context in which one lives (extrapersonal), such as one's city or country or environment or religion. 


\section{Goal}
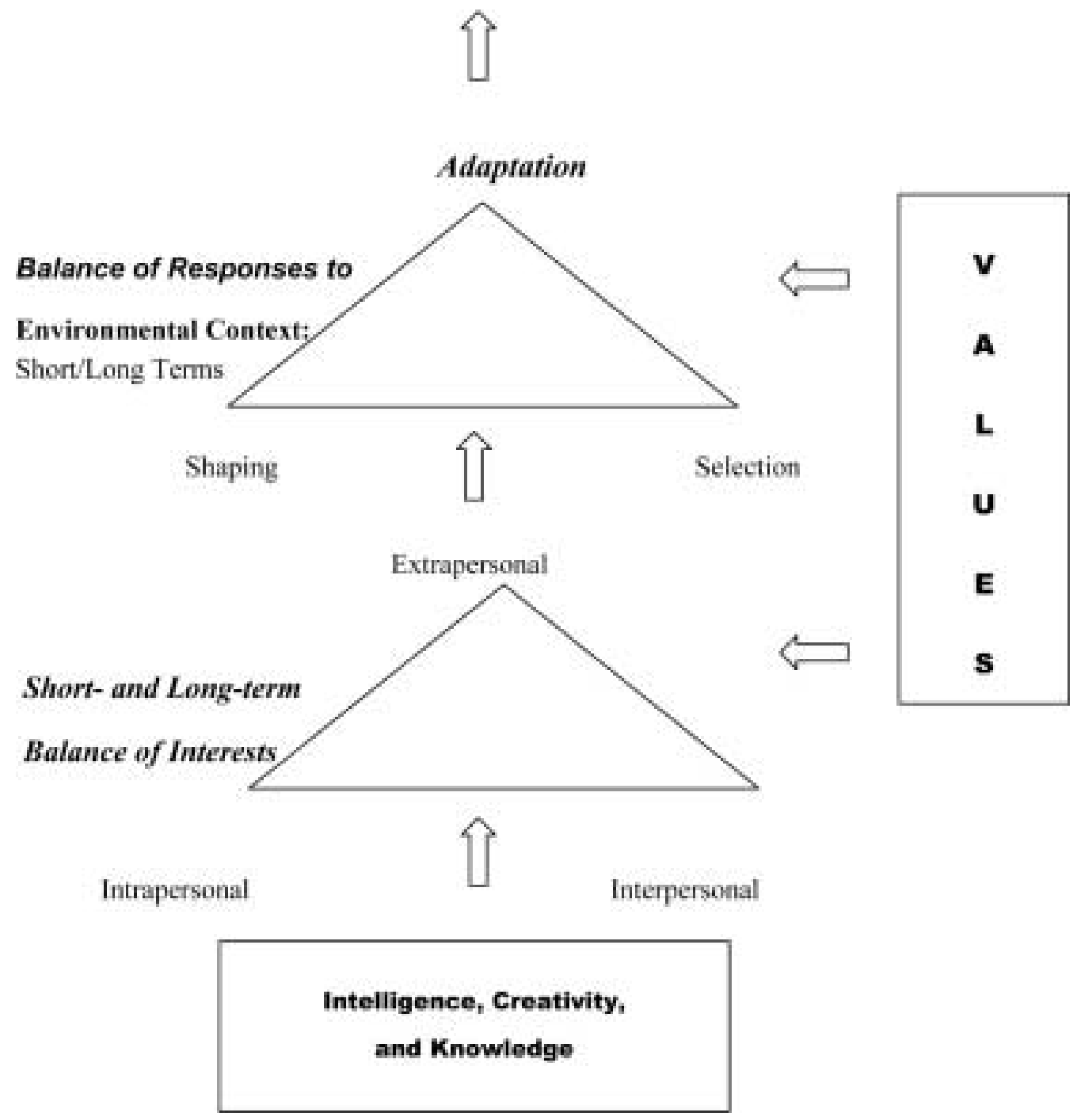

Figure I. The structure of wisdom

An implication of this view is that when one applies intelligence, creativity and knowledge, one may seek deliberately outcomes that are good for oneself and bad for others. In wisdom, however, one certainly may seek good ends for oneself, but one also seeks good outcomes for others. If one's motivations are to maximize certain people's interests and minimize other people's, wisdom is not involved. In wisdom, one seeks a common good, realizing that this common good may be better for some than for others. 
We refer here to 'interests', which are related to the multiple points of view that are a common feature of many theories of wisdom (as reviewed in Sternberg, 1990). Diverse interests encompass multiple points of view, and thus the use of the term 'interests' is intended to include 'points of view'. Sometimes differences in points of view derive not so much from differences in cognitions as from differences in motivations, as when teachers and boards of education have different ideas about how scarce budget dollars should be spent.

Problems requiring wisdom always involve at least some element of each of intrapersonal, interpersonal, and extrapersonal interests. For example, one might decide that it is wise to take a particular teaching position, a decision that seemingly involves only one person. But many people are typically affected by an individual's decision to take a jobsignificant others, children, perhaps parents and friends. In addition, one might consider extrapersonal and long-term interests, such as the societal needs to contribute to the education of new immigrants in urban settings. And the decision always has to be made in the context of the whole range of available options. Similarly, a decision about whether to increase the importance of high-stakes testing requires wisdom because it involves the people who take the tests, their parents, their school, and the society. Wisdom involves a balancing not only of the three kinds of interests, but also of three possible courses of action in response to this balancing: adaptation of oneself or others to existing environments; shaping of environments in order to render them more compatible with oneself or others; and selection of new environments (Sternberg, 1985, 1997). In adaptation, the individual tries to find ways to conform to the existing environment that forms his or her context. Sometimes, adaptation is the best course of action under a given set of circumstances. But typically one seeks a balance between adaptation and shaping, realizing that fit to an environment requires not only changing oneself, but changing the environment as well. When an individual finds it impossible or at least implausible to attain such a fit, he or she may decide to select a new environment altogether, leaving, for example, a job, a community, a marriage, or whatever.

Wise thinking will not develop simply by teaching for other kinds of thinking. It needs to be targeted directly. How might it be nurtured? And why is it so scarce?

\section{Implications for education}

Increases in intelligence - at least as measured by IQ-have not been matched by obvious comparable increases in wisdom. Indeed, to the extent that our society has increasingly stressed the use of IQ to maximize one's own chances of admission to and success in the 'cognitive elite' posited by Herrnstein and Murray (1994), increases in IQ may have been concomitant with decreases in wisdom. High IQ with a scarcity of wisdom has brought us a world with the power to finish itself off many times over.

Wisdom might bring us a world that would seek instead to better itself and the conditions of all the people in it. At some level, we as a society have a choice. What do we wish to maximize through our schooling? Is it only knowledge? Is it only intelligence? Or is it knowledge, intelligence, and wisdom too? If it is wisdom too, then we can put our students on a much different course. We can value not only how students use their individual 
abilities to maximize their own attainments but how they use these abilities to maximize the attainments of others as well. We can, in short, value wisdom.

What would an education look like that valued wisdom? Consider the principles we are using to promote the development of wisdom in middle-school students in the US public schools. In our newly designed curriculum, we infused wisdom-related instruction into the teaching of American history.

Principles of teaching for wisdom derived from the balance theory of wisdom

Teachers who teach for wisdom will explore with students the notion that conventional abilities and achievements are not enough for a satisfying life. Many people become trapped in their lives and, despite feeling conventionally successful, feel that their lives lack fulfillment. Fulfillment is not an alternative to success, but rather, is an aspect of it that, for most people, goes beyond money, promotions, large houses, and so forth. The teacher will further demonstrate and encourage students to consider how wisdom is critical for a satisfying life. In the long run, wise decisions benefit people in ways that foolish decisions never do. The teacher can teach students the usefulness of interdependence-a rising tide raises all ships; a falling tide can sink them.

It is also useful to role model wisdom, because what you do is more important than what you say. Typical school matters, ranging from classroom discipline issues to student elections, could offer teachers and students multiple opportunities to demonstrate and practise wisdom. By helping students learn to properly balance competing interests and goals involved in much of everyday decision-making, teachers can instill new, more caring ways of participating in a school community. Teachers can help students recognize their own interests, those of other people, and those of institutions. They will teach students that the 'means' by which the end is obtained matters, not just the end.

Students can be encouraged to form, critique, and integrate their own values in their thinking. They can read about wise judgments and decision making in the context of the actions that followed so that the students understand that such means of judging and decision making exist. They further can learn to think dialectically (Hegel, 1931), realizing that both questions and their answers evolve over time, and that the answer to an important life question can differ at different times in one's life (such as whether to marry). Wisdom further requires students to learn to think dialogically, whereby they understand interests and ideas from multiple points of view. For example, what one group views as a 'settler', another may view as an 'invader'. Most importantly, students can learn to search for and then try to reach the common good-a good where everyone wins and not only those with whom one identifies.

Teaching for wisdom will succeed only if teachers encourage and reward wisdom. Teachers can make wisdom real for students' lives. Teachers can teach students to monitor events in their lives and their own thought processes about these events. One way to learn to recognize others' interests is to begin to identify your own. They also can help students understand the importance of inoculating oneself against the pressures of unbalanced self-interests and small-group interests. 
Students will develop wisdom by becoming engaged in class discussions, projects, and essays that encourage them to discuss the lessons they have learned from both classical and modern works and how these lessons can be applied to their own lives and the lives of others. They can study not only 'truth', as we know it, but values. The idea is not to forcefeed a set of values, but to encourage students reflectively to develop their own prosocial ones.

Students can be encouraged to think about how almost everything they study might be used for better or worse ends, and to realize that the ends to which knowledge is put do matter. Teachers can realize that the only way they can develop wisdom in their students is to serve as role models of wisdom themselves. A role model of wisdom will take a much more Socratic approach to teaching than teachers customarily do. Students often want large quantities of information spoon-fed or even force-fed to them. They then attempt to memorize this material for exams, only to forget it soon thereafter. In a wisdom-based approach to teaching, students will need to take a more active role in constructing their learning. But a wisdom-based approach is not, in my view, tantamount to a constructivist approach to learning. Students have not achieved or even come close to achieving wisdom when they merely have constructed their own learning. Rather, they must be able to construct knowledge not only from their own point of view, but also to construct and sometimes reconstruct knowledge from the point of view of others. Constructivism from only a single point of view can lead to egocentric rather than balanced understanding.

Lessons taught to emphasize wisdom would have a rather different character from lessons as they are often taught today. Consider examples.

First, social studies and especially history lessons would look very different. For example, high school American history books typically teach American history from only one point of view, that of the new Americans. Thus Columbus is referred to as having 'discovered' America, a strange notion from the standpoint of the many occupants who already lived there when it was 'discovered'. The conquest of the southwest and the Alamo also are presented only from the point of view of the new settlers, not from the standpoint of, say, the Mexicans who lost roughly half their territory. This kind of ethnocentric and frankly propagandistic teaching would have no place in a curriculum that sought to develop wisdom and an appreciation of the need to balance interests.

Second, science teaching would not be about facts presented as though they are the final word. Science is often taught as though it represents the end point of a process of evolution of thought rather than one of many midpoints (Sternberg, 1998b). Students could scarcely realize from this kind of teaching that the paradigms of today, and thus the theories and findings that emanate from them, will eventually be superseded, much as the paradigms, theories, and findings of yesterday were replaced by those of today. Students further can learn that, contrary to the way many textbooks are written, the classical 'scientific method' is largely a particular approach rather than a fixed set of processes and that scientists are as susceptible to fads as are members of other groups. In other words, it is important that students interact critically with information presented in science textbooks.

Third, teaching of literature can reflect a kind of balance that is often absent. The study of literature can be done in the context of the study of history, so that the characters and 
events are interpreted using an appropriate frame of reference. The banning of books often reflects the application of certain contemporary standards to literature, standards of which an author from the past never could have been aware. We will discuss this in more detail further on.

Fourth, through study abroad and exchange programs, we can promote the learning of foreign languages through interactions with native speakers in their cultural contexts. We suggest that many students have so much difficulty learning foreign languages not because they lack the ability but because they lack the motivation. They do not see the need to learn another language. People might be better off, we suggest, if they made more of an attempt wisely to understand other cultures rather than just to expect people from other cultures to understand them. And learning the language of a culture is a key to understanding. People might be less quick to impose their cultural values on others if they understood the others' cultures values. It is also interesting to speculate on why Esperanto, a language that was to provide a common medium of communication across cultures, has been a notable failure. We suggest it is because Esperanto is embedded in no culture at all. It is the language of no one.

Culture cannot be taught, in the context of foreign-language learning, in the way it now often is - as an aside divorced from the actual learning of the language. It should be taught as an integral part of the language - as a primary context in which the language is embedded. The vituperative fights we see about bilingual education and about use of Spanish in the US or French in Canada are not just or even primarily fights about language. They are fights about culture, and they are fights in need of wise resolutions.

Finally, as implied throughout these examples, the curriculum needs to be far more integrated. Literature needs to be integrated with history, science with history and social policy studies, foreign language with culture. Even within disciplines, far more integration is needed.

\section{Teaching wisdom programmatically}

School can help enhance wise thinking skills in students, and next we describe a curriculum program that we have developed to help teachers teach for wisdom.

The program reviewed here, Teaching for Wisdom, was designed to facilitate the development of wise and critical thinking skills in middle school children through the infusion of these skills into a history curriculum (Reznitskaya \& Sternberg, 2004). The aim was to enhance students' wise and critical thinking skills, as well as their knowledge of American history, although the history of any other country might have been used instead. First, we examine how a theoretical model can be transcribed into guidelines for developing a classroom curriculum. We then show examples of the implementation of the curriculum in a number of public middle schools.

Teaching for Wisdom is based on Sternberg's $(1998,200 \mathrm{I})$ balance theory of wisdom, reviewed above, which posits in essence that wise thinking involves the ability to use one's intelligence in the service of a common good by balancing one's own interests with those of other people and of a broader community over both the short- and long-terms. Although it is a complex model accounting for real behaviors in real contexts, it is possible 
to apply the theory in a concrete, real-world setting, as we have done in this program. How was it done?

We believe that the goal of teaching for wisdom can be achieved by providing students with educational contexts where students can formulate their own understanding of what constitutes wise thinking. In other words, teaching for wisdom is not accomplished through a didactic method of 'imparting' information about wisdom and subsequently assessing students with multiple-choice questions. Instead, students need to actively experience various cognitive and affective processes that underlie wise decision-making. In other words, teachers can provide scaffolding for the development of wisdom, but they cannot teach particular courses of actions, or give students a list of do's and don'ts, regardless of circumstances.

What then are the processes underlying wise thinking that students have to acquire, and how can they be introduced into the classroom? Sternberg (200I) outlines pedagogical principles and procedures derived from the theory of wisdom. The fundamental idea behind all these educational guidelines is that the instructor teaches children not what to think, but, rather, how to think.

Let us review here six procedures for teaching for wisdom. Many of these procedures are already in use by classroom teachers, and what we strive for in our curriculum is not so much to revolutionize teaching and make instructors rotate their educational practices I 80 degrees, but rather, to help teachers systematically and frequently implement sound teaching procedures that foster wise thinking.

\section{Procedure I. Encourage students to read classic works of literature and philosophy (whether} western or otherwise) to learn and reflect on the wisdom of the sages

The rush to dump classic works in favor of modern works makes sense only if the wisdom these modern works had to impart equaled or exceeded that of the classic works. When discussing the readings, encourage students to engage in reflective thinking, to reflect on their own functioning to increase their metacognition (Flavell, 1987), that is, their awareness of their cognitions, emotions and beliefs. The process of making a wise decision requires an ongoing monitoring of selected strategies, as well as an ability to modify less successful strategies to better fit the situational demands. Teachers can help students develop wise thinking by designing instructional activities that allow students to explore and shape their own values. Also, students can be explicitly instructed in useful metacognitive strategies such as self-questioning or the use of self-monitoring checklists. For example, in our history curriculum, students study the ideas of the intellectual movement of the Enlightenment and the character of Benjamin Franklin. In one activity, students first read Franklin's maxims published in Poor Richard's almanac, such as 'Whatever is begun in anger ends in shame', 'Be slow in choosing a friend, slower in changing', 'Well done is better than well said', etc (Franklin, 1983). Next, students work in pairs to describe to their partners their own past experiences where one of the Franklin's maxims could apply. Students are then invited to think of a maxim they have learned from their own past and to continue writing their maxims in a notebook or a journal throughout the school year. From this activity, students learn about the benefits of reflecting on one's life experiences and 
thinking about a general rule or maxim they can apply to new situations. Wisdom involves an ability to learn from the past, whether your own or that of other people. Reflective thinking about one's life experiences is an important skill that students get to practice in this activity. Also, having students generate their own maxims throughout the year helps to make reflection on various life experiences a habit of mind.

Procedure 2. Engage students in class discussions, projects, and essays that encourage them to discuss the lessons they have learned from the literary and philosophical works they've read, and how these lessons can be applied to their own lives and the lives of others

In our history curriculum, for example, we make salient the relationships between history and personally relevant everyday experiences. When studying the character of Benjamin Franklin, students examine his accomplishments at improving his own community, such as the establishment of a post office and a library. Students then consider the needs of their own school and classroom communities and devise a plan to address these needs. The goal of such activities is to allow students to see the relevance of historical figures and events to their own lives in order to develop their ability to benefit from past experience and to become active contributors to contemporary history.

Engagement in open discussions and school projects like the one just described should help students develop dialogical and dialectical thinking, in addition to the reflective thinking described earlier. What is dialogical thinking? When one is faced with a complex problem involving several points of view, it is often necessary to take into account different frames of reference and various perspectives to find the best possible solution. What may at first appear as the right answer may turn out to be the wrong choice when the long-term is considered, or when the interests of the community as a whole are taken into account. In dialogical thinking, one uses multiple frames of reference to generate and deliberate about various perspectives on the issue at hand. Optimal solutions come from careful weighing of alternatives, rather than from following one single prescribed course of action. In the classroom, teachers can nourish students' ability to think dialogically by proposing activities in which multiple points of view are presented and discussed. Some empirical studies that have investigated the effectiveness of student discussions for the development of dialogical thinking show improvements in students' ability to resolve illstructured problems following their participation in the discussions (Kuhn et al., 1997; Reznitskaya et al., 200I). In our history curriculum, one example of an activity that fosters the development of dialogical thinking comes from the historical topic of British colonial polices in the late eighteenth century. In this activity, students read multiple accounts (primary historical sources) of events during the Boston Massacre. The reports include an excerpt from a colonial newspaper, an account by a British captain, and an interview with a Boston shoemaker. Students discuss the origins of the differences among the accounts and evaluate the relative credibility of the sources. They are also invited to write their own account of the Boston Massacre events and to consider how their own frames of reference affect their descriptions. From this activity, students learn to appreciate the importance of multiple standpoints, the constructed nature of knowledge, and the powerful influences of one's perspective on one's view of the world. 
Whereas dialogical thinking involves the consideration and weighing of multiple points of view, dialectical thinking emphasizes the consideration and integration of two opposing perspectives. The first perspective considered is the thesis. For example, one can be a radical pacifist and opposed to any military presence or intervention, whatever the circumstances. A second perspective, an antithesis (a negation of the original statement) is then considered. For example, one can argue that people can only live freely and in peace if their borders are protected by armed forces. Finally, a synthesis or reconciliation of the two seemingly opposing statements is developed. For example, one might decide that borders under dispute should be protected by a third party, such as an international army, rather than having the opposing countries measure their military strength against each other. The process does not stop when the two opposing views are reconciled; on the contrary, each synthesis becomes a new thesis, which can then be integrated in a new round of dialectical thinking. In the classroom, dialectical thinking can be encouraged through opportunities to study different sources, enabling students to build their own knowledge, or through writing assignments that explicitly call for a thesis, antithesis, and synthesis. Empirical studies have investigated the impact of developing such a fluid and dynamic concept of knowledge, where the source of knowledge is not the 'authority' (the teacher or the book), but rather, the student. Such conceptions of knowledge have been shown to relate to active engagement in learning (see McDevitt, 1990), persistence in performing a task (see Dweck \& Leggett, 1988), and deeper comprehension and integration of the material taught (see Songer \& Linn, 199I; Qian \& Alvermann, 2000).

An example of an activity where students get to practise their dialectical thinking in our curriculum comes from the same unit on the colonial independence movement. In this activity, students first study the writings of Thomas Paine and Charles Inglis, who express two opposing views on the question of whether America should break away from England. Next, students consider a compromise solution proposed by Joseph Galloway, who attempts to reconcile the two conflicting positions. Students then discuss the notion of compromise and propose their own resolutions to the British-American conflict. Through this activity, students practise synthesizing and reconciling opposing perspectives. They also learn to recognize that the same questions can be answered differently at different points in time.

Procedure 3. Encourage students to study not only 'truth' but values, as developed during their reflective thinking

In our curriculum, students were presented with Benjamin Franklin's maxims and encouraged to engage in reflective thinking. In the homework related to that classroom activity, students are asked to study an excerpt from Franklin's autobiography, where Franklin describes his plan to achieve moral perfection. Having read Franklin's plan, students choose three values that they consider important, and develop their own plan to improve their characters. Students then monitor their behavior for a period of one week and record in a journal their successes and failures at practising the chosen values. This activity allows students to explore, form and apply their own values. Also, students are given an 
opportunity to monitor events in their daily lives and to recognize the connections between values and actions.

Procedure 4. Place an increased emphasis on critical, creative, and practical thinking in the service of good ends that benefit the common good

In the typical classroom, teachers encourage critical thinking skills in their students. Some teachers also aim to develop creative and practical thinking skills (Sternberg \& Grigorenko, 2000 ) by engaging students in activities that lead them to go beyond the content they have studied (creative thinking) in order to apply this knowledge to their environment (practical thinking). To enhance wise thinking, however, students can also be encouraged to consider the outcome of their thinking, and to keep in mind that the best solution is not the one that benefits only the individual doing the thinking, but rather the one that helps others as well. The common good should be the guiding principle in choosing between different possible solutions. For example, in another unit of our history curriculum, students study the topic of slavery in America. In one of the activities, students are encouraged to consider the various reasons underlying the choice of importing slaves to work on the sugar cane plantations. Through readings and classroom discussions, students learn about the analytical, practical, and creative reasons behind the Europeans' choice to import free labor from Africa (need for cheap labor, possibility to import free laborers from Africa who were more resistant to European diseases than Native Americans and well adapted to a tropical climate, etc). Students are led to consider and debate the analytical reasons for this choice, and shown the limitations of choices made purely on the basis of self-interest: importing free labour may have furthered the goal of increased power and financial wealth for the European settlers, but was it the best solution to the need for more plantation workers?

Procedure 5. Encourage students to think about how almost any topic they study might be used for better or worse ends, and about how important that final end is

As described under Procedure 4, students can be encouraged to seek different solutions and to choose the one that benefits the common good rather than the individual. They should also be brought to realize that, just as there are different solutions benefiting different people, a given concept or point of knowledge can be used to a good or poor end.

The end to which one chooses to apply one's knowledge matters greatly. For example, in the unit on American slavery, we ask students to consider the consequences that technological inventions, such as cotton gin, had on slaves and slave owners. Through reading and classroom discussions, students learn that while the cotton gin increased the prosperity of the plantation owners, it also led to the intensification of slavery and increased human suffering. In the related activity, students discuss the values that underlie past and present choices of technology. For example, students realize that when choosing fast food or microwaves, we value time and cost over food quality and health, or when driving cars we implicitly value convenience and time over safety and environment. Thus, students 
become aware of the multiple consequences of given decisions, and learn to analyze their own choices in relation to a variety of interests and goals.

\section{Procedure 6. Remember that a teacher is a role model}

To role model wisdom, the teacher adopts a Socratic approach to teaching, and invites students to play a more active role in constructing learning - from their own point of view and from that of others. Wise thinking is not a set of rules or decisions that the teacher can outline for students to copy down; it is a type of thinking that the students themselves need to adopt and master. The most effective way to encourage wise thinking skills is not through memory drills but through student participation and teacher modeling. For example, a teacher can capitalize on a negative event, such as two students getting into a fight, as a way to demonstrate how one can approach a similar situation in a more constructive way. The teacher can model wise thinking by saying:

When I get into the situations like this, I try to see the dispute from the perspective of the other person and think about whether my own behavior contributed to the situation. Was there anything I could have done differently to prevent this confrontation? Is there a solution to our disagreement that is acceptable to both of us?

Also, teachers may wish not to miss the opportunity to recognize and praise good judgments made by students, such as when they show consideration for others and their ideas, or when they offer a solution that benefits the class as a whole rather than themselves as individuals. The most effective teacher is likely to be one who can create a classroom community in which wisdom is practised, rather than preached. Wisdom can be attained in real life and not just on paper, and it can lead to a more harmonious existence.

The examples we have cited to show how the principles of the balance theory of wisdom can be applied to instruction and infused into a curriculum are all excerpts from two units we developed for use in middle school US history classrooms. 'While we chose to integrate the teaching for wisdom into a subject matter of history, we do not believe that wisdom is limited to history-wise thinking skills can be infused in most subject areas and at most grade levels. While researchers are still trying to determine at which age children are able to engage in higher-order thinking (see Stein \& Miller, 1993), we observed that most of the procedures described here can be adapted from at least the end of elementary school. Let us briefly review how the procedures and principles for wise thinking can be used in other subject areas, as discussed earlier in this text.

In science teaching, dialectical thinking can be applied to illustrate to students the notion that scientific facts are not eternal or immutable, but rather the state of affairs as we perceive them at this very specific point in time. How many scientists in his time considered as scientific evidence the data presented by Galileo Galilei to demonstrate that the Earth revolved around the Sun, and not vice versa? Students also need to understand that scientific method is susceptible to being subverted by ideology or considerations of political expediency, as in case of the Soviet biologist Trofim Lysenko. Ostensibly following strict scientific procedures Lysenko, in fact, manufactured results to align them with the ideological postulates and expectations of the Communist Party leadership. 
Wise thinking skills can also be applied in the literature classroom. Literature is often taught in terms of the standards and context of the contemporary American scene. Characters often are judged in terms of our contemporary standards rather than in terms of the standards of the time and place in which the events took place. One example is the opposition by a parent from an Arizona school district to the study of Mark Twain's Huckleberry Finn in her daughter's high school English class because the book contains the word 'nigger'. The parent felt that this would exacerbate already existing racial tensions in the school. In the words of Circuit Judge Reinhard, who ruled on the case:

The setting is a freshman English class in Tempe, Arizona, and the competing interests are the First Amendment rights of high school students to receive information or ideas-even when contained in literary works that may in today's world appear to have racist overtones-and the rights of those same students to receive a public education that neither fosters nor acquiesces in a racially hostile environment. (Monteiro vs. Tempe Union High School District, 97-155II, U.S. 9th Circuit Court of Appeals, October 19, 1998)

The Appeals Court eventually ruled against the banning of books.

The foreign language classroom is another terrain for enhancing students' wise thinking skills. Foreign languages should be taught in the cultural context in which they are embedded, requiring students to engage in reflective and dialogical thinking to grasp the foreign culture and to position themselves and their experiences in relation to this culture. It tends to be more common in Europe to speak one or several languages beyond one's mother tongue. Perhaps American students have so much more difficulty learning foreign languages than do children in much of Europe not because they lack the ability, but because they lack the motivation and the exposure. An American student would probably much more readily see the need to learn a foreign language if each of the 50 states spoke a different language, much like the member states of the European Union do. We would also do our students a service by teaching them to understand other cultures rather than just to expect people from other cultures to understand them. Learning the language of a culture is a key to understanding it, and the two cannot be taught separately or by viewing culture as an appendix to language rather than the context in which it is deeply rooted. Wise people understand not only their own culture, but other cultures, and learning languages helps us achieve such understanding.

\section{Conclusion}

The road to this new approach to education, via the balance theory of wisdom, is bound to be a rocky one. First, entrenched structures, whatever they may be, are difficult to change, and wisdom is neither taught in schools nor, in general, is it even discussed. Second, many people will not see the value of teaching something that shows no promise of raising conventional test scores. These scores, which formerly were predictors of more interesting criteria, have now become criteria, or ends, in themselves. Society has lost track of why they ever mattered in the first place and they have engendered the same kind of mindless competition we see in people who relentlessly compare their economic achievements with those of others. Third, wisdom is much more difficult to develop than is the kind of achievement that can be developed and then readily tested via multiple-choice tests. Finally, people 
who have gained influence and power in a society via one means are unlikely to want either to give up that power or to see a new criterion be established on which they do not rank as favorably.

There is no easy road to wisdom. There never was, and probably never will be. As an educational system, we have turned on the easy road, but the wrong road. It is not too late to turn back. By ratcheting up our emphasis on a narrow conception of what it means to be a 'good student', we are ignoring the broader conception that will make a difference to individuals and society. It is not merely what we know, but how we use it, that will determine the fate of our society and of others.

\section{Acknowledgements}

Preparation of this article was supported by a grant from the W. T. Grant Foundation. Grantees undertaking such projects are encouraged to express freely their professional judgment. This article, therefore, does not necessarily represent the positions or the policies of the W. T. Grant Foundation.

\section{Notes}

I. Additional information on these units can be obtained by visiting the PACE web site at http:// pace.tufts.edu/, or by sending an inquiry to robert.sternberg@tufts.edu.

\section{Notes on contributors}

Robert J. Sternberg is Dean of the School of Arts and Sciences at Tufts University.

Linda Jarvin is Adjunct Associate Professor and Deputy Director of the Center for the Psychology of Abilities, Competencies, and Expertise at Tufts University.

Alina Reznitskaya is Assistant Professor of Psychology at Montclair State University.

\section{References}

Baltes, P. B. \& Smith, J. (in press) Wisdom: the orchestration of mind and virtue (Boston, Blackwell).

Dweck, C. S. \& Leggett, E. L. (1988) A social-cognitive approach to motivation and personality, Psychological Review, 95, 256-273.

Flavell, J. H. (1987) Speculations about the nature and development of metacognition, in: F. E. Wienert \& R. H. Kluwe (Eds) Metacognition, motivation, and understanding (Hillsdale, NJ, Erlbaum), 2I-29.

Flynn, J. R. (1998) IQ gains over time: toward finding the causes, in: U. Neisser (Ed.) The rising curve: longterm gains in IQ and related measures (Washington, DC, American Psychological Association), 25-66.

Franklin, B. (1983) Poor Richard's almanac (White Plains, NY, Peter Pauper Press). (Original work published 1733, 1749, 1756, 1757, 1758.)

Gardner, H. (1983) Frames of mind: the theory of multiple intelligences (New York, Basic Books).

Hegel, G. W. F. (I93I) The phenomenology of the mind (London, Allen \& Unwin). (Original work published 1807.)

Herrnstein, R. J. \& Murray, C. (1994) The bell curve (New York, Free Press).

Kuhn, D., Shaw, V. \& Felton, M. (1997) Effects of dyadic interaction on argumentative reasoning, Cognition and Instruction, 15, 287-315. 


\section{8}

R. J. Sternberg et al.

McDevitt, T. M. (1990) Mothers' and children's beliefs about listening, Child Study Journal, 20, 105-128.

Neisser, U. (Ed.) (1998) The rising curve (Washington, DC, American Psychological Association).

Qian, G. \& Alvermann, D. E. (2000) Relationship between epistemological beliefs and conceptual change learning, Reading and Writing Quarterly, 16, 59-74.

Reznitskaya, A., Anderson, R. C., McNurlen, B., Nguyen-Jahiel, K., Archodidou, A. \& Kim, S. (200I) Influence of oral discussion on written argument, Discourse Processes, 32, I55-175.

Reznitskaya, A. \& Sternberg, R. J. (2004) Teaching students to make wise judgments: the 'teaching for wisdom' program, in: P. A. Linley \& S. Joseph (Eds) Positive psychology in practice (New York, Wiley), $18 \mid-196$.

Songer, N. B. \& Linn, M. C. (199I) How do views of science influence knowledge integration, Journal of Research in Science Teaching, 28, 76I-784.

Stein, N. L. \& Miller, C. A. (1993) A theory of argumentative understanding: relationships among position preference, judgments of goodness, memory, and reasoning, Argumentation, 7, 183-204.

Sternberg, R. J. (1985) Beyond IQ: a triarchic theory of human intelligence (New York, Cambridge University Press).

Sternberg, R. J. (Ed.) (1990) Wisdom: its nature, origins, and development (New York, Cambridge University Press).

Sternberg, R. J. (1997) Successful intelligence (New York, Plume).

Sternberg, R. J. (1998a) A balance theory of wisdom, Review of General Psychology, 2, 347-365.

Sternberg, R. J. (1998b) The dialectic as a tool for teaching psychology, Teaching of Psychology, 25, I77-I80.

Sternberg, R. J. (200I) Why schools should teach for wisdom: the balance theory of wisdom in educational settings, Educational Psychologist, 36(4), 227-245.

Sternberg, R. J. (Ed.) (2002) Why smart people can be so stupid (New Haven, CT, Yale University Press).

Sternberg, R. J. (2003) A duplex theory of hate: development and application to terrorism, massacres, and genocide, Review of General Psychology, 7(3), 299-328.

Sternberg, R. J. \& Grigorenko, E. L. (2002) Teaching for successful intelligence (Arlington Heights, IL, Skylight).

Sternberg, R. J. \& Jordan, J. (Eds.) (2005) Handbook of wisdom: psychological perspectives (New York, Cambridge University Press).

Webster's new world dictionary (1997) Webster's new world dictionary (New York, Simon \& Schuster). 